\title{
Increasing trends in central obesity among Chinese adults with normal body mass index, 1993-2009
}

Tingting $\mathrm{Du}^{1+}$, Xingxing Sun ${ }^{2+}$, Ping $\mathrm{Yin}^{3}$, Rui Huo ${ }^{1}$, Chaochao $\mathrm{Ni}^{1}$ and Xuefeng $\mathrm{Yu}^{{ }^{1 *}}$

\begin{abstract}
Background: Central obesity is thought to be more pathogenic than overall obesity and studies have shown that the association between waist circumference (WC) and mortality was strongest in those with a normal body mass index (BMI). The objective of our study was to determine secular trends in the prevalence of central obesity (WC $\geq 90 \mathrm{~cm}$ for men and $\geq 80 \mathrm{~cm}$ for women) among Chinese adults with normal BMl from 1993 to 2009 and to examine the impact of performance of combined BMI and WC on the prevalence of obesity in Chinese adults.
\end{abstract}

Methods: We used data from the China Health and Nutrition Survey (CHNS) conducted from 1993 to 2009. From which we included a total of 52023 participants aged $\geq 18$ years.

Results: The age-standardized prevalence of central obesity among Chinese adults with BMl $<25 \mathrm{~kg} / \mathrm{m}^{2}$ increased from 11.9\% in 1993 to $21.1 \%$ in 2009 (P for linear trend <0.001). The upward trends were noted in both genders, all ages, rural/urban settings, and education groups (all $P$ for linear trend $<0.001$ ), with greater increments in men, participants aged 18-64 years, and rural residents ( $P$ for interaction terms survey $\times$ sex, survey $\times$ age, and survey $\times$ rural/urban settings were $0.042,0.003$, and $<0.001$, respectively). Trends in the prevalence of central obesity were similar when a more stringent $\mathrm{BMI}<23 \mathrm{~kg} / \mathrm{m}^{2}$ cut point (Asian cut point) was applied. Central obesity is associated with a higher risk of incident hypertension within normal BMI category. More than $65 \%$ individuals with obesity would be missed if solely BMI was measured.

Conclusions: We observed an upward trend in the prevalence of central obesity among participants with normal BMI irrespective of sex, age, rural/urban settings, and education level. Central obesity is associated with a higher risk of incident hypertension within normal BMI category. Approximately two thirds of the individuals with obesity would be missed if WC was not measured. It is, therefore, urgent to emphasize the importance of WC as a measure to monitor the prevalence of obesity.

Keywords: Body mass index, Waist circumference, Central obesity, General obesity, CHNS

\section{Background}

Despite the evidence that body mass index (BMI) is a key component of choice to provide a standardized definition of obesity for the purposes of national surveillance and international comparisons [1], the prevalence of obesity as defined by BMI should be interpreted cautiously as it is a poor indicator of body fat distribution [2]. Since waist circumference (WC) is strongly correlated with central fat

\footnotetext{
*Correspondence: xfyu188@163.com

${ }^{\dagger}$ Equal contributors

'Department of Endocrinology, Tongji Hospital, Tongji Medical College of Huazhong University of Science and Technology, Wuhan 430030, PR China Full list of author information is available at the end of the article
}

localization [3], it is a sensitive measure of central-type obesity. Epidemiological studies have revealed that excess deposition of fat in the abdominal region seemed to be a risk factor for numerous adverse health outcomes independently of general adiposity reflected by BMI [4-6]. The prevalence of general obesity and central obesity as measured by BMI and WC, respectively, are well-documented and both of them have increased dramatically worldwide [7-14]. Interestingly, significant increase in the prevalence of central obesity seems to be more pronounced than that of general obesity at given periods in both China and other countries $[8-10,13,15]$. Hence, the diagnostic use of

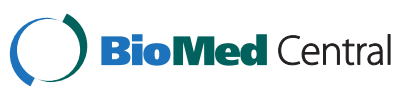


WC may to some degree have a particularly significant impact on the current epidemiological landscape of obesity. Studies have also illustrated that a larger increase in central obesity may not be related to the change in BMI [9]. Hence, it is very likely that a great number of subjects with normal BMI category may suffer from central obesity. Since the US National Institutes of Health recommended that WC be measured to screen for increased disease risk only among individuals in the overweight and obese categories of BMI [16], information on the prevalence of central obesity within normal category of BMI is scant $[9,10]$, particularly in China. Relatively few health care professionals in China routinely measure WC, particularly in individuals with normal category of BMI. In addition, accumulating studies conducted in China indicated that central obesity was more important as a predictor of diabetes, hypertension, metabolic syndrome and cardiovascular disease than general obesity [17-19]. Furthermore, emerging evidence suggested that WC was also associated with higher risk of myocardial infarction or all-cause mortality within all categories of BMI $[4,20]$. Hence, our study aimed to describe the secular trends in the prevalence of central obesity among Chinese adults with normal BMI from 1993 to 2009, and to evaluate the impact on the prevalence of obesity if both BMI and WC were measured.

\section{Methods}

\section{Study design}

We used data from the China Health and Nutrition Survey (CHNS) for our analysis. The CHNS, an ongoing international collaborative project between the Carolina Population Center at the University of North Carolina at Chapel Hill and the National Institute of Nutrition and Food Safety at the Chinese Center for Disease Control and Prevention, is the only large-scale longitudinal, household-based survey in China [21]. It was designed to explore how the social and economic transformation of Chinese society is affecting the health and nutritional status of the Chinese population. The CHNS rounds were conducted in 1989, 1991, 1993, 1997, 2000, 2004, 2006, 2009 and 2011. For each round, a stratified multistage, random cluster process was employed to draw study sample from nine provinces (Liaoning, Heilongjiang, Jiangsu, Shandong, Henan, Hubei, Hunan, Guangxi and Guizhou), covering approximately $56 \%$ of China's population, that vary significantly in terms of geography, economic development, and health status. Counties in the nine provinces were stratified by income (low, middle and high) and a weighted sampling scheme was used to select randomly four counties in each province. Full details of the CHNS have been described elsewhere [21]. Each participant provided a written informed consent and the study was approved by institutional review board from the University of North Carolina at Chapel Hill and the National Institute for Nutrition and Food Safety, China Center for Disease Control and Prevention.

\section{Study population}

Since WC was initially collected in 1993, this study examined data from CHNS: 1993, 1997, 2000, 2004, 2006, and 2009. There were 64308 participants included in these six surveys. All participants were asked to complete a structured questionnaire which provided information on age, sex, degree of urbanization (urban vs. rural), educational attainment, a history of diabetes and so on. They also underwent detailed physical examinations that included weight, height, WC and blood pressure (BP). Participants were included in the present analysis if they were 18 years or older. Pregnant women or participants with missing information on age, WC, BMI, or BP, extreme or implausible WC (51 cm or $190 \mathrm{~cm}$ ), BMI, or BP values were excluded from analysis. The remaining analytic sample sizes for the current study were 7274 for 1993, 8368 for 1997, 9369 for 2000, 8948 for 2004, 8786 for 2006, and 9278 for 2009.

\section{Measurements}

Weight, height, WC and BP were measured following standardized protocols from the World Health Organization (WHO) $[22,23]$. Weight was measured with the participants wearing light clothing on a calibrated beam scale and height was measured without shoes using a portable stadiometer. BMI was calculated as weight (kilogram) divided by squared height (meter), rounded to the nearest tenth. WC was measured with an inelastic tape to the nearest $0.1 \mathrm{~cm}$ at a midpoint between the bottom of the rib cage and the top of the iliac crest at the end of exhalation. BP was measured by trained examiners using a mercury sphygmomanometer at three different consecutive times at 3-5 min intervals on one visit. The three readings were averaged as the BP values in our data analysis. All physical examinations were performed at the same location and followed the same protocol at each study visit.

\section{Definitions}

According to WHO suggestions [22], normal weight is defined as BMI $<25 \mathrm{~kg} / \mathrm{m}^{2}$, general obesity is defined as BMI $\geq 30 \mathrm{~kg} / \mathrm{m}^{2}$. According to WHO expert consultation for Asians [24], normal weight is defined as BMI $<23 \mathrm{~kg} / \mathrm{m}^{2}$. According to the criteria recommended by Working Group on Obesity in China [25], general obesity is defined as BMI $\geq 28 \mathrm{~kg} / \mathrm{m}^{2}$. According to the International Diabetes Federation recommendations for Asians [26], central obesity is defined as $W C \geq 90 \mathrm{~cm}$ for men and $\geq 80 \mathrm{~cm}$ for women. According to the Seventh Joint National Committee on Prevention, Detection, 
Evaluation, and Treatment of High Blood Pressure guidelines [23], hypertension is defined as systolic $\mathrm{BP} \geq 140$ $\mathrm{mmHg}$, diastolic $\mathrm{BP} \geq 90 \mathrm{mmHg}$, and/or self-reported treatment of hypertension with antihypertensive medication in the last 2 weeks.

\section{Statistical analysis}

All statistical analyses were conducted using SPSS software (version 16.0 for windows; SPSS, Chicago, IL, USA). Continuous variables were presented as means and standard deviations (SD). Categorical variables were expressed as numbers or percentages. One-way ANOVA was applied to compare differences in means across groups. A Chi-square test was performed to assess differences of proportions across groups. Analyses were stratified by sex, age group (18-44 years, 45-64 years, and of 65 years or older), degree of urbanization (urban vs. rural), and educational attainment (less than high school, high school, and university). The estimated prevalence was age-standardized to 2000 census of the Chinese adult population by the direct method. Trends in the prevalence of central obesity among participants with BMI $<25 \mathrm{~kg} / \mathrm{m}^{2}$ from 1993 to 2009 were assessed by Cochran-Armitage trend testing. A sensitivity analysis was performed using a more stringent $\mathrm{BMI}<23$ $\mathrm{kg} / \mathrm{m}^{2}$ cut point (Asian cut point) rather than the WHO BMI $<25 \mathrm{~kg} / \mathrm{m}^{2}$ cut point. To assess whether changes throughout the 17-year period differed by sex, logistic regression analysis was utilized to examine potential interaction effects between cohort and sex. Similar processes were repeated separately for age, rural/urban and education groups. Venn diagram was constructed as a visual display of central obesity based on WC and general obesity based on BMI. Of 7274 individuals participated in 1993, we excluded 1351 participants with hypertension and 440 participants who did not attend any follow-up visits. The final sample size for incidence analyses of hypertension was 5483 persons. Cox proportional-hazards models were used to predict the incident hypertension from WC within BMI categories. A two-tailed $P$ value of $<0.05$ was considered to be statistically significant.

\section{Results}

The percentages of women remained relatively stable during the period covered by the surveys ( $\mathrm{P}$ for trend $>0.05$ ) (Table 1). The mean age increased successively from 1993 to $2009(\mathrm{P}<0.01)$.
Secular trends in the prevalence of central obesity among participants with $\mathrm{BMI}<25 \mathrm{~kg} / \mathrm{m}^{2}$

Detailed information on trends in the age-standardized prevalence of central obesity according to $\mathrm{WHO}$ criteria for Asians among subjects with BMI $<25 \mathrm{~kg} / \mathrm{m}^{2}$ were shown for overall and by sex, age, degree of urbanization, and educational attainment in Table 2. The prevalence of central obesity doubled approximately from $11.9 \%$ in 1993 to $21.1 \%$ in 2009 (P for linear trend < 0.001). In stratified analysis, although the prevalence among women approximately tripled that among men in each survey (all $\mathrm{P}<0.001$ ), the change in the prevalence of central obesity was more striking among men than that among women, with the prevalence escalated from 4.4 to $10.4 \%$ among men and from 19.3 to $30.9 \%$ among women. The gender dependent changes were further confirmed by the significant interaction terms (survey $\times \operatorname{sex})(p=0.042)$. For each survey, the age-specific prevalence of central obesity increased with age (all P for trend $<0.01$ ). In addition, for each age group, the prevalence of central obesity increased linearly across the study periods $(\mathrm{P}<0.001)$. However, the prevalence of central obesity increased more rapidly among participants 18-64 years of age than that among those aged $\geq 65$ years $(P=0.003$ for interaction terms survey $\times$ age). The prevalence of central obesity increased progressively over the six study periods in both rural and urban settings (both P for trend $<0.001$ ). Notably, the change in the prevalence was particularly pronounced among participants residing in rural settings $(\mathrm{P}<0.001$ for interaction terms survey $\times$ rural/urban settings). For each education group, the prevalence of central obesity increased progressively over the 6 surveys (all $\mathrm{P}$ for trend $<0.001$ ). Although the prevalence was much higher among participants in the lowest education group (less than high school) than among those in the middle education group (high school) or the highest education group (university) ( $\mathrm{P}<0.001$ for each survey), the increments in the prevalence of central obesity did not differ by education groups $(\mathrm{P}=0.67$ for interaction terms survey $\times$ education groups).

When a more stringent BMI $<23 \mathrm{~kg} / \mathrm{m}^{2}$ cut point (Asian cut point) rather than the BMI $<25 \mathrm{~kg} / \mathrm{m}^{2}$ cut point was applied, results were similar (Table 3 ), but with a relatively lower prevalence of central obesity. Furthermore, the increments in the prevalence of central obesity among participants with BMI $<23 \mathrm{~kg} / \mathrm{m}^{2}$ during the period 1993-2009 did not differ by sex and age

Table 1 Unadjusted demographic characteristics of Chinese adults aged $\geq 18$ years: the CHNS 1993-2009

\begin{tabular}{|c|c|c|c|c|c|c|}
\hline & 1993 & 1997 & 2000 & 2004 & 2006 & 2009 \\
\hline & $\overline{(n=7274)}$ & $\overline{(n=8368)}$ & $\overline{(n=9369)}$ & $\overline{(n=8948)}$ & $\overline{(n=8786)}$ & $\overline{(n=9278)}$ \\
\hline Women (\%) & 52.0 & 51.1 & 51.6 & 52.1 & 52.9 & 52.4 \\
\hline Age $(y$, Mean \pm SD) & $42.1 \pm 15.6$ & $43.5 \pm 15.8$ & $44.9 \pm 15.5$ & $48.0 \pm 15.3$ & $49.1 \pm 15.1$ & $50.6 \pm 15.3$ \\
\hline
\end{tabular}


Table 2 Age-standardized prevalence of central obesity ${ }^{*}$ among Chinese adults with BMI $<25 \mathrm{~kg} / \mathrm{m}^{2}$

\begin{tabular}{|c|c|c|c|c|c|c|c|c|c|c|c|c|c|c|}
\hline & \multicolumn{2}{|c|}{1993} & \multicolumn{2}{|c|}{1997} & \multicolumn{2}{|c|}{2000} & \multicolumn{2}{|c|}{2004} & \multicolumn{2}{|c|}{2006} & \multicolumn{2}{|r|}{2009} & \multirow{2}{*}{$\begin{array}{l}P \text { for } \\
\text { trend }^{\dagger}\end{array}$} & \multirow[t]{2}{*}{$P^{*}$} \\
\hline & $n$ & $\%$ (SE) & $\mathrm{n}$ & $\%$ (SE) & $\mathrm{n}$ & $\%$ \% (SE) & $\mathrm{n}$ & $\%$ (SE) & $n$ & $\%$ (SE) & $n$ & $\%$ (SE) & & \\
\hline Total & 5060 & $11.9(0.4)$ & 5346 & $12.2(0.4)$ & 5281 & $15.8(0.4)$ & 4722 & $18.2(0.5)$ & 4485 & $18.6(0.5)$ & 4597 & $21.1(0.5)$ & $<0.001$ & \\
\hline Men & 2538 & $4.4(0.4)$ & 2695 & $4.6(0.4)$ & 2652 & $7.7(0.4)$ & 2274 & $10.1(0.5)$ & 2119 & $8.9(0.5)$ & 2160 & $10.4(0.5)$ & $<0.001$ & 0.042 \\
\hline Women & 2522 & $19.3(0.7)$ & 2651 & $19.8(0.7)$ & 2629 & $23.8(0.7)$ & 2448 & $26.0(0.8)$ & 2366 & $27.4(0.8)$ & 2437 & $30.9(0.8)$ & $<0.001$ & \\
\hline \multicolumn{15}{|l|}{ Age (years) } \\
\hline $18-44$ & 3228 & $7.7(0.4)$ & 3202 & $8.4(0.4)$ & 2941 & $11.0(0.5)$ & 2229 & $13.5(0.6)$ & 2054 & $13.6(0.7)$ & 1948 & $15.1(0.7)$ & $<0.001$ & 0.003 \\
\hline $45-64$ & 1351 & $17.7(0.9)$ & 1515 & $17.7(0.8)$ & 1665 & $22.3(0.8)$ & 1727 & $24.9(0.9)$ & 1629 & $25.5(0.9)$ & 1770 & $34.9(0.9)$ & $<0.001$ & \\
\hline $65-118$ & 481 & $23.1(1.7)$ & 629 & $22.2(1.5)$ & 675 & $29.8(1.5)$ & 766 & $30.2(1.4)$ & 802 & $32.0(1.4)$ & 879 & $35.3(1.4)$ & $<0.001$ & \\
\hline \multicolumn{15}{|l|}{ Region } \\
\hline Urban & 1407 & $15.7(0.9)$ & 1694 & $12.7(0.7)$ & 1640 & $16.3(0.8)$ & 1497 & $18.4(0.8)$ & 1432 & $19.8(0.9)$ & 1461 & $20.8(0.9)$ & $<0.001$ & $<0.001$ \\
\hline Rural & 3653 & $9.6(0.4)$ & 3652 & $11.3(0.5)$ & 3641 & $14.7(0.5)$ & 3225 & $17.2(0.6)$ & 3053 & $17.1(0.6)$ & 3136 & $20.1(0.6)$ & $<0.001$ & \\
\hline \multicolumn{15}{|l|}{ Education } \\
\hline Less than high school & 4226 & $12.8(0.5)$ & 4347 & $13.0(0.5)$ & 4162 & $16.5(0.5)$ & 3690 & $19.0(0.6)$ & 3411 & $18.9(0.6)$ & 3441 & $22.4(0.6)$ & $<0.001$ & 0.67 \\
\hline High school & 706 & $9.3(1.0)$ & 827 & $10.0(0.9)$ & 895 & $14.8(1.0)$ & 595 & $17.3(1.3)$ & 588 & $17.5(1.3)$ & 582 & $19.6(1.4)$ & $<0.001$ & \\
\hline University & 128 & $10.5(2.3)$ & 172 & $11.1(2.1)$ & 224 & $12.2(1.9)$ & 437 & $14.5(1.4)$ & 486 & $17.0(1.4)$ & 574 & $16.4(1.3)$ & $<0.001$ & \\
\hline
\end{tabular}

SE, standard error.

* Central obesity is defined as waist circumference $\geq 90 \mathrm{~cm}$ for men and $\geq 80 \mathrm{~cm}$ for women.

+ Trends in the prevalence of central obesity from 1993 to 2009 were assessed by Cochran-Armitage trend testing.

${ }^{\ddagger} \mathrm{P}$ for interaction terms (survey $\times$ sex, survey $\times$ age, survey $\times$ rural/urban settings, and survey $\times$ education group) were assessed by logistic regression analysis.

$(\mathrm{P}=0.49$ and 0.18 for interaction terms survey $\times$ sex and survey $\times$ age, respectively).

\section{Overlap between obesity diagnosed by BMI and WC criteria} For each survey, among those identified to have general or central obesity based on a combination of BMI $\geq 28 \mathrm{~kg} / \mathrm{m}^{2}$ and $\mathrm{WC} \geq 90 / 80 \mathrm{~cm}$, central obesity detected by WC occupied almost the whole percentage ( $\geq 95.3 \%$ ) (1-the percentage of exclusive BMI $\geq 28 \mathrm{~kg} / \mathrm{m}^{2}$ ); Most individuals who were identified with general obesity according to BMI criterion were also suffered from central obesity, as few participants $(\leq 4.7 \%)$ were diagnosed exclusively with general obesity; Considerable participants $(\geq 75.7 \%)$ were diagnosed exclusively with central obesity (Figure 1 and Table 4). Similar trends were noted in both genders for each survey. The prevalence of exclusively general obesity

Table 3 Age-standardized prevalence of central obesity ${ }^{*}$ among Chinese adults with BMI $<23 \mathrm{~kg} / \mathrm{m}^{2}$

\begin{tabular}{|c|c|c|c|c|c|c|c|c|c|c|c|c|c|c|}
\hline & \multicolumn{2}{|c|}{1993} & \multicolumn{2}{|c|}{1997} & \multicolumn{2}{|c|}{2000} & \multicolumn{2}{|c|}{2004} & \multicolumn{2}{|c|}{2006} & \multicolumn{2}{|c|}{2009} & \multirow{2}{*}{$\begin{array}{l}\mathrm{P} \text { for } \\
\text { trend }^{\dagger}\end{array}$} & \multirow[t]{2}{*}{$P^{\neq}$} \\
\hline & $n$ & $\%$ (SE) & $n$ & $\%$ (SE) & $n$ & $\%$ (SE) & $n$ & $\%$ (SE) & $n$ & $\%$ (SE) & $n$ & $\%$ (SE) & & \\
\hline Total & 5060 & $7.6(0.4)$ & 5346 & $7.6(0.4)$ & 5281 & $10.2(0.4)$ & 4722 & $12.1(0.5)$ & 4485 & $11.5(0.5)$ & 4597 & $13.5(0.6)$ & $<0.001$ & \\
\hline Men & 2538 & $2.5(0.3)$ & 2695 & $2.2(0.3)$ & 2652 & $4.5(0.4)$ & 2274 & $5.8(0.5)$ & 2119 & $4.3(0.5)$ & 2160 & $4.9(0.5)$ & $<0.001$ & 0.49 \\
\hline Women & 2522 & $13.0(0.7)$ & 2651 & $13.3(0.7)$ & 2629 & $16.1(0.8)$ & 2448 & $18.2(0.9)$ & 2366 & $18.1(0.9)$ & 2437 & $21.2(0.9)$ & $<0.001$ & \\
\hline \multicolumn{15}{|l|}{ Age (years) } \\
\hline $18-44$ & 3228 & $4.9(0.4)$ & 3202 & $5.4(0.4)$ & 2941 & $7.6(0.5)$ & 2229 & $9.3(0.6)$ & 2054 & $8.9(0.7)$ & 1948 & $9.6(0.7)$ & $<0.001$ & 0.18 \\
\hline $45-64$ & 1351 & $11.1(0.9)$ & 1515 & $10.4(0.8)$ & 1665 & $13.0(0.9)$ & 1727 & $15.6(1.0)$ & 1629 & $14.6(1.0)$ & 1770 & $18.3(1.0)$ & $<0.001$ & \\
\hline 65-118 & 481 & $15.7(1.8)$ & 629 & $14.6(1.5)$ & 675 & $19.3(1.7)$ & 766 & $21.1(1.7)$ & 802 & $20.8(1.6)$ & 879 & $26.0(1.7)$ & $<0.001$ & \\
\hline \multicolumn{15}{|l|}{ Region } \\
\hline Urban & 1407 & $10.5(0.9)$ & 1694 & $7.6(0.7)$ & 1640 & $10.8(0.8)$ & 1497 & $12.3(0.9)$ & 1432 & $12.3(1.0)$ & 1461 & $13.0(1.0)$ & $<0.001$ & $<0.0001$ \\
\hline Rural & 3653 & $6.2(0.4)$ & 3652 & $7.2(0.4)$ & 3641 & $9.4(0.5)$ & 3225 & $11.5(0.6)$ & 3053 & $10.6(0.6)$ & 3136 & $12.9(0.7)$ & $<0.001$ & \\
\hline \multicolumn{15}{|l|}{ Education } \\
\hline Less than high school & 4226 & $8.3(0.5)$ & 4347 & $8.3(0.4)$ & 4162 & $10.4(0.5)$ & 3690 & $12.6(0.6)$ & 3411 & $11.7(0.6)$ & 3441 & $14.3(0.7)$ & $<0.001$ & 0.73 \\
\hline High school & 706 & $6.2(1.2)$ & 827 & $5.6(0.9)$ & 895 & $10.3(1.1)$ & 595 & $12.1(1.6)$ & 588 & $10.9(1.5)$ & 582 & $12.1(1.8)$ & $<0.001$ & \\
\hline University & 128 & $8.0(2.5)$ & 172 & $6.8(2.0)$ & 224 & $8.8(2.0)$ & 437 & $9.7(1.5)$ & 486 & $11.5(1.5)$ & 574 & $11.6(1.4)$ & $<0.001$ & \\
\hline
\end{tabular}

$\mathrm{SE}$, standard error.

${ }^{*}$ Central obesity is defined as waist circumference $\geq 90 \mathrm{~cm}$ for men and $\geq 80 \mathrm{~cm}$ for women.

${ }^{\dagger}$ Trends in the prevalence of central obesity from 1993 to 2009 were assessed by Cochran-Armitage trend testing.

${ }^{\ddagger} \mathrm{P}$ for interaction terms (survey $\times$ sex, survey $\times$ age, survey $\times$ rural/urban settings, and survey $\times$ education group) were assessed by logistic regression analysis. 


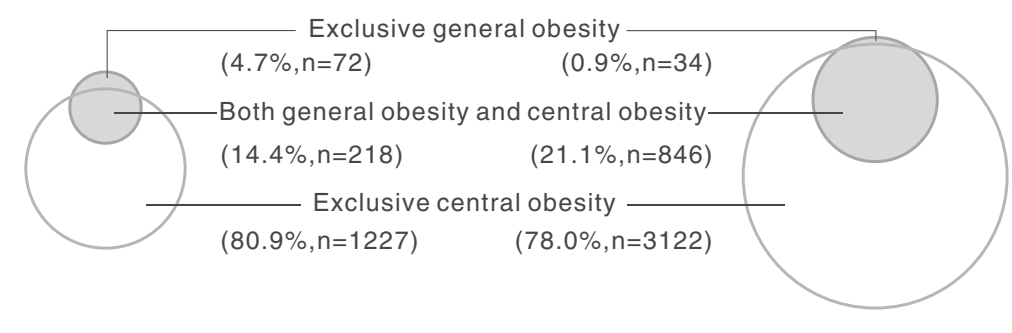

CHNS 1993

CHNS 2009

Figure 1 Venn Diagrams for obesity based on either WC or BMI criteria. WC criterion for obesity: waist circumference (WC) $\geq 90 \mathrm{~cm}$ for men and $\geq 80 \mathrm{~cm}$ for women. BMl criterion for obesity: body mass index (BMI) $\geq 28 \mathrm{~kg} / \mathrm{m}^{2}$.

among men significantly exceeded that among women in each survey (all $\mathrm{P}<0.05$ ). Of note, the proportions of exclusive central obesity based on WC criterion surpassed $65 \%$ in each subgroup.

Results were remarkably similar when a sensitivity analysis was conducted: using the BMI $\geq 30 \mathrm{~kg} / \mathrm{m}^{2}$ rather than the more restrictive Asian $\mathrm{BMI} \geq 28 \mathrm{~kg} / \mathrm{m}^{2}$ cut point to define general obesity, but with an even lower prevalence of exclusive general obesity (Additional file 1).

\section{HRs for high WC-related hypertension}

In participants with $\mathrm{BMI}<25 \mathrm{~kg} / \mathrm{m}^{2}$, the hazard ratio (HR) for incident hypertension from central obesity compared with those with normal WC was 1.8 (95\% CI, 1.6 to 2.0 ) (Table 5). After adjustment for confounding variables, this association was attenuated $(1.4,1.2$ to 1.6 in model 1 , and $1.3,1.1$ to 1.5 in in model 2$)$ but still significant $(\mathrm{P}<0.01)$.
When a more restrictive BMI cut point $\left(\mathrm{BMI}<23 \mathrm{~kg} / \mathrm{m}^{2}\right)$ was applied, results were similar.

\section{Discussion}

The present data provide evidence that the prevalence of central obesity among Chinese adults with BMI $<25 \mathrm{~kg} / \mathrm{m}^{2}$ increased significantly from 1993 to 2009. The upward trend was noted irrespective of sex, age, rural/urban settings, and education groups. Notably, the prevalence of central obesity increased more rapidly among men than that among women. The increment was more prominent among participants aged 18-64 years than that among those aged $\geq 65$ years. Participants residing in rural settings saw a more rapid increase in the prevalence compared with counterparts residing in urban settings. Central obesity is associated with a higher risk of incident hypertension within normal BMI category. Approximately two thirds of

Table 4 Overlap* between BMI- and WC- based obesity among Chinese adults

\begin{tabular}{|c|c|c|c|c|c|c|c|c|c|c|c|c|}
\hline & \multicolumn{2}{|c|}{1993} & \multicolumn{2}{|c|}{1997} & \multicolumn{2}{|c|}{2000} & \multicolumn{2}{|c|}{2004} & \multicolumn{2}{|c|}{2006} & \multicolumn{2}{|c|}{2009} \\
\hline & $\mathbf{n}$ & $\%$ & $\mathbf{n}$ & $\%$ & $\mathbf{n}$ & $\%$ & $\mathbf{n}$ & $\%$ & $\mathbf{n}$ & $\%$ & $\mathrm{n}$ & $\%$ \\
\hline \multicolumn{13}{|l|}{ Total } \\
\hline $\mathrm{BMI} \geq 28 \mathrm{~kg} / \mathrm{m}^{2}$ or $W C \geq 90 / 80 \mathrm{~cm}$ & 1517 & $\ldots$ & 2097 & $\ldots$ & 3021 & $\ldots$ & 3362 & $\ldots$ & 3469 & $\ldots$ & 4002 & $\ldots$ \\
\hline Exclusive BMI $\geq 28 \mathrm{~kg} / \mathrm{m}^{2}$ & 72 & 4.7 & 64 & 3.1 & 86 & 2.8 & 103 & 3.1 & 105 & 3.0 & 34 & 0.9 \\
\hline Exclusive WC $\geq 90 / 80 \mathrm{~cm}$ & 1227 & 80.9 & 1626 & 77.5 & 2296 & 76.0 & 2555 & 76.0 & 2627 & 75.7 & 3122 & 78.0 \\
\hline Both $\mathrm{BMl} \geq 28 \mathrm{~kg} / \mathrm{m}^{2}$ and $W C \geq 90 / 80 \mathrm{~cm}$ & 218 & 14.4 & 407 & 19.4 & 639 & 21.2 & 704 & 20.9 & 737 & 21.3 & 846 & 21.1 \\
\hline \multicolumn{13}{|l|}{$\overline{M e n}$} \\
\hline $\mathrm{BMI} \geq 28 \mathrm{~kg} / \mathrm{m}^{2}$ or $\mathrm{WC} \geq 90 / 80 \mathrm{~cm}$ & 387 & $\ldots$ & 648 & $\ldots$ & 992 & $\ldots$ & 1128 & $\ldots$ & 1146 & $\ldots$ & 1363 & $\ldots$ \\
\hline Exclusive $\mathrm{BMI} \geq 28 \mathrm{~kg} / \mathrm{m}^{2}$ & 47 & 12.1 & 49 & 7.5 & 49 & 4.9 & 66 & 5.9 & 70 & 6.1 & 28 & 2.1 \\
\hline Exclusive $W C \geq 90 / 80 \mathrm{~cm}$ & 270 & 69.8 & 430 & 66.4 & 676 & 68.2 & 780 & 69.1 & 794 & 69.3 & 985 & 72.3 \\
\hline Both $\mathrm{BMl} \geq 28 \mathrm{~kg} / \mathrm{m}^{2}$ and $W C \geq 90 / 80 \mathrm{~cm}$ & 70 & 18.1 & 169 & 26.1 & 267 & 26.9 & 282 & 25.0 & 282 & 24.6 & 350 & 25.6 \\
\hline \multicolumn{13}{|l|}{ Women } \\
\hline $\mathrm{BMI} \geq 28 \mathrm{~kg} / \mathrm{m}^{2}$ or $W C \geq 90 / 80 \mathrm{~cm}$ & 1130 & $\ldots$ & 1449 & $\ldots$ & 2029 & $\ldots$ & 2234 & $\ldots$ & 2323 & $\ldots$ & 2639 & $\ldots$ \\
\hline Exclusive BMI $\geq 28 \mathrm{~kg} / \mathrm{m}^{2}$ & 25 & 2.2 & 15 & 1.1 & 37 & 1.8 & 37 & 1.7 & 35 & 1.5 & 6 & 0.2 \\
\hline Exclusive $W C \geq 90 / 80 \mathrm{~cm}$ & 957 & 84.7 & 1196 & 82.5 & 1620 & 79.8 & 1775 & 79.5 & 1833 & 78.9 & 2137 & 81.0 \\
\hline Both $\mathrm{BMI} \geq 28 \mathrm{~kg} / \mathrm{m}^{2}$ and $W C \geq 90 / 80 \mathrm{~cm}$ & 148 & 13.0 & 238 & 16.4 & 372 & 18.4 & 422 & 18.8 & 455 & 19.6 & 496 & 18.8 \\
\hline
\end{tabular}

"Proportions of obesity based on both WC $\geq 90 / 80 \mathrm{~cm}$ and BMI $\geq 28 \mathrm{~kg} / \mathrm{m}^{2}$ (overlap between BMI- and WC- based obesity) is calculated as the number of obesity based on both $W C \geq 90 / 80 \mathrm{~cm}$ and $\mathrm{BMI} \geq 28 \mathrm{~kg} / \mathrm{m}^{2}$ divided by the number of obesity based on either WC $\geq 90 / 80 \mathrm{~cm}$ or BMI $\geq 28 \mathrm{~kg} / \mathrm{m}^{2}$.

Likewise, proportions of exclusive general obesity and exclusive central obesity are calculated by the similar procedure. 
Table 5 Hazard ratios for high WC-related incidence of hypertension within each BMI category

\begin{tabular}{|c|c|c|c|c|c|c|c|c|}
\hline & \multicolumn{4}{|c|}{ BMI categories } & \multicolumn{4}{|c|}{ BMI categories } \\
\hline & \multicolumn{2}{|c|}{$\mathrm{BMI}<25 \mathrm{~kg} / \mathrm{m}^{2}$} & \multicolumn{2}{|c|}{$\mathrm{BMI} \geq 25 \mathrm{~kg} / \mathrm{m}^{2}$} & \multicolumn{2}{|c|}{$\mathrm{BMI}<23 \mathrm{~kg} / \mathrm{m}^{2}$} & \multicolumn{2}{|c|}{$\mathrm{BMI} \geq 23 \mathrm{~kg} / \mathrm{m}^{2}$} \\
\hline & $\begin{array}{c}\mathrm{WC}<90 / 80 \\
\mathrm{~cm}\end{array}$ & $\begin{array}{c}W C \geq 90 / 80 \\
\mathrm{~cm}\end{array}$ & $\begin{array}{c}W C<90 / 80 \\
\mathrm{~cm}\end{array}$ & $\begin{array}{c}W C \geq 90 / 80 \\
\mathrm{~cm}\end{array}$ & $\begin{array}{c}W C<90 / 80 \\
\mathrm{~cm}\end{array}$ & $\begin{array}{c}W C \geq 90 / 80 \\
\mathrm{~cm}\end{array}$ & $\begin{array}{c}W C<90 / 80 \\
\mathrm{~cm}\end{array}$ & $\begin{array}{c}W C \geq 90 / 80 \\
\mathrm{~cm}\end{array}$ \\
\hline $\begin{array}{l}\text { Unadjusted model } \\
\text { (HR, 95\% Cl) }\end{array}$ & 1 & $1.8(1.6-2.0)$ & 1 & $1.1(0.9-1.4)$ & 1 & $1.6(1.3-2.0)$ & 1 & $1.5(1.3-1.8)$ \\
\hline $\begin{array}{l}\text { Adjusted model } 1^{*} \\
(\mathrm{HR}, 95 \% \mathrm{Cl})\end{array}$ & 1 & $1.4(1.2-1.6)$ & 1 & $1.0(0.7-1.4)$ & 1 & $1.2(1.0-1.6)$ & 1 & $1.3(1.1-1.6)$ \\
\hline Adjusted model $2^{\dagger}$ & 1 & $1.3(1.1-1.5)$ & 1 & $1.0(0.7-1.3)$ & 1 & $1.2(1.0-1.4)$ & 1 & $1.2(1.0-1.5)$ \\
\hline
\end{tabular}

(HR, 95\% Cl)

*Adjusted model 1 was adjusted for sex, age, degree of urbanization, education, smoking status, alcohol consumption.

${ }^{\dagger}$ Adjusted model 2 was adjusted for all the variables in model 2 plus systolic blood pressure and diastolic blood pressure.

$\mathrm{BMI}$, body mass index; WC, waist circumference, $\mathrm{HR}$, hazard ratio, $\mathrm{Cl}$, confidence interval.

the individuals with obesity would be missed if screening by BMI alone.

As regards the prevalence of central obesity in subjects with BMI $<25 \mathrm{~kg} / \mathrm{m}^{2}$, the findings from our present study are in line with the results obtained in the Pilot Study of the Fitness of Australians, where $6.5 \%$ of men and $22.0 \%$ of women with BMI $<25 \mathrm{~kg} / \mathrm{m}^{2}$ are in a risk category based on WC [15]. In addition, two studies suggest an independent increase in the prevalence of central obesity over and above the prevalence of general obesity in adults $[9,10]$. Besides, a number of studies demonstrate a steeper rise in the prevalence of central obesity than the prevalence of general obesity although these studies do not indicate whether the central obesity has moved independently further than the general obesity $[8,10,13]$. Our finding that an increasing number of people with BMI $<25 \mathrm{~kg} / \mathrm{m}^{2}$ are at risk for obesity due to excessive WC $(\geq 90 / 80 \mathrm{~cm})$ emphasizes the huge potential for preventing an unexpectedly large burden of obesity that remains to be realized in Chinese adults with BMI $<25 \mathrm{~kg} / \mathrm{m}^{2}$. A recent study showed that among women, the association between WC and mortality was strongest in those with a normal BMI [20]. In addition, we found that approximately two thirds of individuals with obesity would be missed if WC is not taken into account for identification of obesity. An understanding of this issue is important for clinical reasons as weight management is a key strategy to the treatment of people with metabolic disturbance $[27,28]$. Therefore, obese cases with metabolic disturbance deserve high priority in risk factor modification. Evidence from studies show that achieving healthy weight through controlling weight adequately in obese patients could decrease blood pressure levels, improve lipid profile and insulin resistance [27]. The current study also shows that a higher WC is associated with a higher risk of incident hypertension within normal BMI category. It is of particular concern that most individuals in China on a visit to a doctor undergo assessment of body composition only by BMI for convenience. Given that weight reduction has important implications to reduce the burden of obesity-related disease, it is, therefore, necessary and crucial to make efforts to promote the measurement of WC in clinical practice. In addition, evidence from studies show that a substantial number of subjects with metabolic disturbance do not always conform to general obesity assessed by BMI. The degree of adiposity associated with a given level of BMI varies by racial and ethnic groups. Relative to blacks, a BMI of $20-25 \mathrm{~kg} / \mathrm{m}^{2}$, which would be considered lean within blacks, corresponds to an elevated body fat content in Asian populations as they tend to have higher body fat percentages at this BMI level and possible less favorable health [29-31]. Indeed, BMI may simply reflect increased muscle mass in athletes, which does not brought them less favorable health as lean body mass is inversely related to allcause mortality [32]. Hence, measuring WC could provide additional meaningful information beyond that provided by BMI for accurately predicting obesity-associated complications and an opportunity for proper intervention.

The finding from the current study that central obesity is observed more commonly in females than in males is similar to the results from other studies $[8,11]$. For instance, the prevalence of central obesity was $16.1 \%$ in men and $37.6 \%$ in women in the study of InterASIA [11]. One possible explanation for our tripling central obesity prevalence in women might be attributable to the fact that we adopted a threshold of $80 \mathrm{~cm}$ to diagnose central obesity in women and the mean WC of women is close to this cut-off point (data not shown), it is likely that women are more prone to exceed this threshold to be defined as central obesity when their WC increases. However, the root causes that lead to differential prevalence of central obesity in men and women warrants further study.

Explanations for the higher prevalence of exclusive general obesity in men than that in women might be due to the differences in body composition between men and women, with men tending to have a greater skeletal muscle than women and women tending to have a greater percentage of body fat than men [33,34], which 
further supported the notion that the performance of BMI in distinguishing fat mass from lean mass is limited.

Similar to the study of ENRICA [8], the frequency of central obesity increases with age in our study. Evidence from a study demonstrates that aging is associated with an increased accumulation of central fat [35]. Given a greater increment in the prevalence of central obesity noted among participants aged 18-64 years in our study, it is likely that older populations would bear a huge burden of central obesity when the relatively younger participants getting old. China has experienced extremely rapid increases in economic development, national wealth and lifespan over the last 20 years. Old populations within this transitional country, who have traditionally suffered from facing famine and food shortages, may eventually come to experience the highest risk of central obesity, indicating that urgent implementation of obesity prevention programs in old adults should be prioritized.

Our finding that rural residents saw a more rapid increase in the prevalence of central obesity compared with urban counterparts is also a characteristic observed in other population-based studies in China [13,36]. Given its large population living in rural setting, China may bear a high obesity related burden. Finally, our finding that a higher prevalence of central obesity observed in participants in the lowest education group is in keeping with the results from the previous studies [9,37]. Our results, together with those of previous studies $[10,11,13]$, provide evidence that the burden of obesity also affects the lower social classes in China as educational attainment reflects socioeconomic status to some extent.

Our study has several limitations. First, the sample is partial nationally representative as only nine of China's 31 provinces are included, and therefore, extrapolating results to the whole of China should be interpreted cautiously. Second, other social and environmental variables such as dietary habits and sedentary lifestyle, which would have impact on obesity, were not considered. Third, estimates across subgroups should also be interpreted with caution because of limited sample size. However, our study has several strengths. Firstly, our study maintains a large sample size and includes individuals from urban and rural settings in China, which allows for exploring the prevalence of obesity over a range of demographic groups. Secondly, all study measurements are made by trained staff following a standard protocol. A vigorous quality assurance program and the same strict methodology are used to ensure the quality of the data collection over the entire study period.

\section{Conclusions}

The prevalence of central obesity increased significantly among Chinese adults with normal BMI from 1993 to 2009. The upward trends were noted in genders, all ages, rural/urban settings, and education groups, with greater increases in men, younger participants, and rural residents. Central obesity is an independent risk for incident hypertension in individuals with normal BMI. About 2 in 3 Chinese obese adults would be missed if solely BMI was adopted to define obesity. Results from our present study emphasize the importance of WC for monitoring the prevalence of obesity. Given the stronger association between WC and metabolic risk, measuring both BMI and WC is helpful in more accurately predicting obesityassociated health burden.

\section{Additional file}

Additional file 1: Overlap* between BMI- and WC- based obesity among Chinese adults.

\section{Abbreviations}

BMI: Body mass index; WC: Waist circumference; CHNS: China Health and Nutrition Survey; BP: Blood pressure; WHO: World Health Organization; SD: Standard deviation.

\section{Competing interests}

The authors declare that they have no competing interests.

\section{Authors' contributions}

XFY, TTD conceived the study. XXS, TTD and PY completed all statistical analyses. XXS and TTD drafted the manuscript. XFY, RH, and CCN contributed to the discussion. XFY revised the manuscript. All authors have read and approved the final manuscript.

\section{Acknowledgements}

We thank the China Health and Nutrition Survey, supported by the NIH (R01D30880, DK056350 and R01-HD38700), and the National Institute of Nutrition and Food Safety, China Center for Disease Control and Prevention, Carolina Population Center, the University of North Carolina at Chapel Hill and the Fogarty International Center for providing the data used here.. We also thank the China-Japan Friendship Hospital and Ministry of Health for support for CHNS 2009 survey. The study was supported by National Natural Science Foundation of China 30772207. All errors are the authors' alone.

\section{Author details}

'Department of Endocrinology, Tongji Hospital, Tongji Medical College of Huazhong University of Science and Technology, Wuhan 430030, PR China. ${ }^{2}$ Department of Anesthesiology, School of Stomatology, Fourth Military Medical University, Xi'an 710032, PR China. ${ }^{3}$ Department of Epidemiology and Biostatistics, School of Public Health, Tongji Medical College, Huazhong University of Science and Technology, Wuhan 430030, PR China.

Received: 19 September 2012 Accepted: 1 April 2013

Published: 10 April 2013

\section{References}

1. Bouchard C: How much progress have we made over the last few decades? Int J Obes (Lond) 2008, 32(Suppl 7):S2-S7.

2. Rankinen T, Kim SY, Perusse L, Despres JP, Bouchard C: The prediction of abdominal visceral fat level from body composition and anthropometry: ROC analysis. Int J Obes Relat Metab Disord 1999, 23:801-809.

3. Pouliot MC, Despres JP, Lemieux S, Moorjani S, Bouchard C, Tremblay A, Nadeau A, Lupien PJ: Waist circumference and abdominal sagittal diameter: best simple anthropometric indexes of abdominal visceral adipose tissue accumulation and related cardiovascular risk in men and women. Am J Cardiol 1994, 73:460-468.

4. Yusuf S, Hawken S, Ounpuu S, Bautista L, Franzosi MG, Commerford P, Lang $C C$, Rumboldt Z, Onen CL, Lisheng L, et al: Obesity and the risk of 
myocardial infarction in 27,000 participants from 52 countries: a case-control study. Lancet 2005, 366:1640-1649.

5. Wang Y, Rimm EB, Stampfer MJ, Willett WC, Hu FB: Comparison of abdominal adiposity and overall obesity in predicting risk of type 2 diabetes among men. Am J Clin Nutr 2005, 81:555-563.

6. Reis JP, Macera CA, Araneta MR, Lindsay SP, Marshall SJ, Wingard DL: Comparison of overall obesity and body fat distribution in predicting risk of mortality. Obesity (Silver Spring) 2009, 17:1232-1239.

7. Flegal KM, Carroll MD, Ogden CL, Curtin LR: Prevalence and trends in obesity among US adults, 1999-2008. JAMA 2010, 303:235-241.

8. Gutierrez-Fisac IL, Guallar-Castillon P, Leon-Munoz LM, Graciani A, Banegas $J R$, Rodriguez-Artalejo F: Prevalence of general and abdominal obesity in the adult population of Spain, 2008-2010: the ENRICA study. Obes Rev 2012, 13:388-392.

9. Li C, Ford ES, McGuire LC, Mokdad AH: Increasing trends in waist circumference and abdominal obesity among US adults. Obesity (Silver Spring) 2007, 15:216-224.

10. Walls HL, Stevenson CE, Mannan HR, Abdullah A, Reid CM, McNeil J, Peeters A: Comparing trends in BMI and waist circumference. Obesity (Silver Spring) 2011, 19:216-219.

11. Reynolds K, Gu D, Whelton PK, Wu X, Duan X, Mo J, He J: Prevalence and risk factors of overweight and obesity in China. Obesity (Silver Spring) 2007, 15:10-18.

12. Macia E, Duboz P, Gueye L: Prevalence of obesity in Dakar. Obes Rev 2010, 11:691-694

13. Xi B, Liang Y, He T, Reilly KH, Hu Y, Wang Q, Yan Y, Mi J: Secular trends in the prevalence of general and abdominal obesity among Chinese adults, 1993-2009. Obes Rev 2012, 13:287-296.

14. Wardle J, Boniface D: Changes in the distributions of body mass index and waist circumference in English adults, 1993/1994 to 2002/2003. Int J Obes (Lond) 2008, 32:527-532.

15. Booth ML, Hunter C, Gore CJ, Bauman A, Owen N: The relationship between body mass index and waist circumference: implications for estimates of the population prevalence of overweight. Int J Obes Relat Metab Disord 2000, 24:1058-1061.

16. National Institutes of Health, National Heart Lung and Blood Institute: Clinical Guidelines on the Identification, Evaluation, and Treatment of Overweight and Obesity in Adults--The Evidence Report. National Institutes of Health. Obes Res 1998, 6(Suppl 2):51S-209S.

17. Li G, Chen X, Jang Y, Wang J, Xing X, Yang W, Hu Y: Obesity, coronary heart disease risk factors and diabetes in Chinese: an approach to the criteria of obesity in the Chinese population. Obes Rev 2002, 3:167-172.

18. Zhang X, Shu XO, Gao YT, Yang G, Li H, Zheng W: General and abdominal adiposity and risk of stroke in Chinese women. Stroke 2009, 40:1098-1104.

19. Jia Z, Zhou Y, Liu X, Wang Y, Zhao X, Liang W, Wu S: Comparison of different anthropometric measures as predictors of diabetes incidence in a Chinese population. Diabetes Res Clin Pract 2011, 92:265-271.

20. Jacobs EJ, Newton CC, Wang Y, Patel AV, McCullough ML, Campbell PT, Thun MJ, Gapstur SM: Waist circumference and all-cause mortality in a large US cohort. Arch Intern Med 2010, 170:1293-1301.

21. Popkin BM, Du S, Zhai F, Zhang B: Cohort Profile: The China Health and Nutrition Survey-monitoring and understanding socio-economic and health change in China, 1989-2011. Int J Epidemiol 2010, 39:1435-1440.

22. WHO Expert Committee: Physical status: the use and interpretation of anthropometry. Report of a WHO Expert Committee. World Health Organ Tech Rep Ser 1995, 854:1-452.

23. Chobanian AV, Bakris GL, Black HR, Cushman WC, Green LA, Izzo JL Jr, Jones DW, Materson BJ, Oparil S, Wright JT Jr, et al: The Seventh Report of the Joint National Committee on Prevention, Detection, Evaluation, and Treatment of High Blood Pressure: the JNC 7 report. JAMA 2003, 289:2560-2572.

24. WHO Expert Consultation: Appropriate body-mass index for Asian populations and its implications for policy and intervention strategies. Lancet 2004, 363:157-163.

25. Zhou BF: Predictive values of body mass index and waist circumference for risk factors of certain related diseases in Chinese adults-study on optimal cut-off points of body mass index and waist circumference in Chinese adults. Biomed Environ Sci 2002, 15:83-96

26. Alberti KG, Zimmet $P$, Shaw J: The metabolic syndrome-a new worldwide definition. Lancet 2005, 366:1059-1062.

27. Katzel LI, Bleecker ER, Colman EG, Rogus EM, Sorkin JD, Goldberg AP: Effects of weight loss vs aerobic exercise training on risk factors for coronary disease in healthy, obese, middle-aged and older men. A randomized controlled trial. JAMA 1995, 274:1915-1921.

28. Klein S, Allison DB, Heymsfield SB, Kelley DE, Leibel RL, Nonas C, Kahn R: Waist circumference and cardiometabolic risk: a consensus statement from shaping America's health: Association for Weight Management and Obesity Prevention; NAASO, the Obesity Society; the American Society for Nutrition; and the American Diabetes Association. Diabetes Care 2007, 30:1647-1652.

29. Flegal KM, Shepherd JA, Looker AC, Graubard BI, Borrud LG, Ogden CL, Harris TB, Everhart JE, Schenker N: Comparisons of percentage body fat body mass index, waist circumference, and waist-stature ratio in adults. Am J Clin Nutr 2009, 89:500-508.

30. Aloia JF, Vaswani A, Mikhail M, Flaster ER: Body composition by dual-energy X-ray absorptiometry in black compared with white women. Osteoporos Int 1999, 10:114-119.

31. Gu D, He J, Duan X, Reynolds K, Wu X, Chen J, Huang G, Chen CS, Whelton PK: Body weight and mortality among men and women in China. JAMA 2006, 295:776-783.

32. Kragelund C, Omland T: A farewell to body-mass index? Lancet 2005 , 366:1589-1591.

33. Janssen I, Heymsfield SB, Wang ZM, Ross R: Skeletal muscle mass and distribution in 468 men and women aged 18-88 yr. J Appl Physiol 2000, 89:81-88.

34. Kim J, Wang Z, Heymsfield SB, Baumgartner RN, Gallagher D: Total-body skeletal muscle mass: estimation by a new dual-energy $\mathrm{X}$-ray absorptiometry method. Am J Clin Nutr 2002, 76:378-383.

35. Borkan GA, Norris AH: Fat redistribution and the changing body dimensions of the adult male. Hum Biol 1977, 49:495-513.

36. Wildman RP, Gu D, Muntner P, Wu X, Reynolds K, Duan X, Chen CS, Huang G, Bazzano LA, He J: Trends in overweight and obesity in Chinese adults: between 1991 and 1999-2000. Obesity (Silver Spring) 2008, 16:1448-1453.

37. Jones-Smith JC, Gordon-Larsen P, Siddigi A, Popkin BM: Emerging disparities in overweight by educational attainment in Chinese adults (1989-2006). Int J Obes (Lond) 2012, 36:866-875.

doi:10.1186/1471-2458-13-327

Cite this article as: Du et al:: Increasing trends in central obesity among Chinese adults with normal body mass index, 1993-2009. BMC Public Health 2013 13:327.

\section{Submit your next manuscript to BioMed Central and take full advantage of:}

- Convenient online submission

- Thorough peer review

- No space constraints or color figure charges

- Immediate publication on acceptance

- Inclusion in PubMed, CAS, Scopus and Google Scholar

- Research which is freely available for redistribution 